\title{
Concomitant predation on parasites - removal of trematode-infected snails by predacious fish in a subarctic lake
}

\author{
Miroslava Soldanova ${ }^{1}$, David Thieltges ${ }^{2}$, Jessica Schwelm ${ }^{3}$, Tereza Vyhlídalová ${ }^{4}$, Gabrielle \\ van Beest ${ }^{5}$, Per-Arne Amundsen ${ }^{6}$, Rune Knudsen ${ }^{6}$, Roar Kristoffersen ${ }^{6}$, Eirik Henriksen ${ }^{6}$, \\ Sebastian Prati ${ }^{3}$, and Ana Born-Torrijos ${ }^{5}$ \\ ${ }^{1}$ Biology Centre CAS \\ ${ }^{2}$ Royal Netherlands Institute for Sea Research \\ ${ }^{3}$ University of Duisburg-Essen \\ ${ }^{4}$ University of South Bohemia in Ceske Budejovice Faculty of Science \\ ${ }^{5}$ Biology Centre CAS Institute of Parasitology \\ ${ }^{6}$ UiT The Arctic University of Norway Faculty of Biosciences Fisheries and Economics
}

October 6, 2021

\begin{abstract}
Concomitant predation, which occurs when parasites are consumed and digested along with their hosts, has previously been suggested as a profound factor determining food web structure. Few studies have adressed the impact of concomitant predation in research on behaviourally parasite-modified prey or in biological control studies. However, empirical evidence of concomitant predation effects on hosts infected with multiple parasite taxa is lacking. We investigated the importance of concomitant predation on digenean trematodes by examining the degree of snail (Radix balthica, first intermediate host) seasonal predation by Arctic charr (Salvelinus alpinus) and brown trout (Salmo trutta) by contrasting infection rates of free-living snails obtained from a lake vs predated snails retrieved from fish stomachs and intestines. The fish consumed infected snails nearly at all seasons, demonstrating that concomitant predation in the model subarctic lake is common, likely indirectly affecting trematode transmission by reducing host and parasite populations. The overall trematode prevalence in both snail groups was seasonindependent, being however substantially higher in free-living compared to predated snails. The net effects of underlying mechanisms related to prey availability, fish feeding ecology, continuous presence of dominant trematodes and, most importantly, size of fish and snails drove the strength of predator-prey interactions and infection patterns in both snail groups. Larger fish preying upon larger snails, which simultaneously harboured more infections, may induce a substiantial negative effect of concomitant predation on snail and parasite population dynamics, with serious implications for food web structure and ecosystem functioning. This study contributes to a better understanding of the role of non-host predators in regulating trematode infection, community structure and transmisison patterns, biomass transfer and energy flow in food webs. Our findings also highlight the importance of studying the impact and extent of concomitant predation in terms of parasite seasonal dynamics and biological control of infectious diseases.
\end{abstract}

\section{Hosted file}

Soldanova et al MAIN TEXT.doc available at https://authorea.com/users/439704/articles/540576concomitant-predation-on-parasites-removal-of-trematode-infected-snails-by-predaciousfish-in-a-subarctic-lake 